\title{
ERCIŞLI EMRAH ŞiiRLERININ MÜZIKAL YAPI ÖZELLIKLERI VE BÖLGE KÜLTÜRÜNE TESIRI
}

\author{
Songül Çakmak ${ }^{1 *}$ \\ Van Yüzüncü Yıl Üniversitesi, Türk Müziği Devlet Konservatuarı
}

\begin{abstract}
Özet
Türk topluluklarının sözlü edebiyatlarında şiir en önemli ifade yolu olarak görülmüştür. Yüzyıllar boyunca hafızada yer alan metinlerden iletişim aracı olarak yararlanılarak kuşaklar arası kültürel mirasın aktarılmasında önemli işlevleri üstlenmiştir. Bu sayede sözlü kültürün önemli hafızaları kuşaklararası milli kültürün aktarımını yerine getirebilmiştir. Van sözlü kültürünün aktarılmasında çok büyük bir öneme sahip olan Ercişli Emrah, şiirlerinde yaşadığı coğrafyanın tabiat güzelliklerinin yanı sıra sevgilisine olan aşkını ve özlemini türkülerle anlatırken, bölge sosyo/kültürel yapısı hakkında da önemli bilgileri şiir/müzik metinleri ve gelenekleri vasıtasıyla aktarmıştır. Ercişli Emrah'ın söylemek istediklerini özentisiz bir dille ifade etmiş olması ise çok uzun yıllar hafızalarda yer etmesini sağlamıştır. Çalışma, yöre halkından usta bir âşık olan Ummâni ile yapılan bazı görüşmeler neticesinde büyük saz şairi Ercişli Emrah'ın yaşayan şiirleri ve Emrah geleneğinin bölgenin müzik kültürüne etkisi çerçevesinde derleme yoluyla oluşturulmuştur. Ayrıca çalışmada konuyla ilgili basıımış kaynaklardan ve bölge sözlü kültüründen faydalanılmıştır. Âşık Emrah şiirlerinin ezgi yönü incelenmiş olmakla birlikte, eserlerinin güncellenmesi kapsamında ele alınmış ve halk müziğine ulusal düzeyde katkıları doğrultusunda yorumlanarak analiz edilmiştir.
\end{abstract}

Anahtar Kelimeler: Ercişli Emrah, Türkü, Sözlü Şiir, Müzikal Yapı, Müzik Kültürü

\section{MUSICAL CONSTRUCTION CHARACTERISTICS OF ERCIŞLI EMRAH POETRY AND EFFECT TO} REGIONAL CULTURE

\begin{abstract}
Poetry in the oral literature of the Turkish communities has been considered as the most important way of expression. Memorized texts have been employed as a way of communication and they have served in the transfer of cultural heritage, thus significant memories of oral culture have carried out the transfer of national culture across generations. Ercişli Emrah, who has a very important role in conveying the oral culture of Van, described the natural beauty of geographical area he lived in as well as his love and longing for his beloved by means of his ballads. While doing this, he conveyed important information about socio-cultural form of the region by means of poetry/music. Using a simple style while telling what he wants to tell provided him to be imprinted on the memories. The poems of this great poet have been compiled within the framework of 'the effect of ErcişliEmrah to the music culture of the region'after a few meetings with Ummani (a master poet-singer). In this study, literature review and oral culture of the region have been used. Poet-singer Emrah's poems have been studied melodically and also they have been analyzed to provide an updated version of his works and to stress his contribution to national folk music.
\end{abstract}

Keywords: Ercişli Emrah, Poetry, Musical Form, Culture, Effect

\footnotetext{
${ }^{1}$ Yazışma yapılacak yazar: songulcakmak@yyu.edu.tr
} 


\section{Giriş}

\section{Sözlü Kültür ve Şiir Sanatı}

Söz; manevi mirasın en önemli ve en doğal aracıdır. Tarihin en ince ipleri, görkemli ve kutsal olan ve halkın manevi hayatının tutunduğu her şey, söze odak noktası gibi bağlıdır. Şiir sanatının başlangıcı, dilin oluştuğu o karanlık tarih öncesinde kaybolmaktadır. Dilin oluşumu, insanlık sanatının en öncü, en kararlı ve parlak çabasıdır. Söz, fikrin ifade edilmesi için şartlı gösterge değil, doğanın ve hayatın insanda oluşturduğu edebi tasvirdir. Gelenekler eşliğindeki kadim dönem mitleri, halkın tüm ruhani ilgilerini içeren dil ve şiiri oluşturma yolundaydı. Dilin oluşumunda ve yapısında tek bir bireyin zihniyeti değil, bütün halkın zihniyeti yansımıştır. Atalarımızın bütün düşünce alanı dil ile sınırıydı. Dil yalnızca dışa vurumun değil; tüm halkın ayrılmaz ahlaki faaliyetlerinin bir parçasıydı. Bu halkın içinde her birey aktif katııım içindeydi. Ulusların şiirleri de dilin yaratılığı aynı sözlü kültür gücüyle oluşmuştur. Hatta sanat alanındaki en derin ve en parlak kahramanlar halkın sözlü edebiyatı ile folkloru tarafından yaratılmıştır. Folklorun; halk şiir sanatının, edebiyat hareketinin başlangıcını birincil sözlü kültürdeki bu kahramanlar aracılığıyla geliştirdiği muhakkaktır. Inssanlık gelişiminin erken dönemlerinde yaratılan ürün, yani geleneksel folklorun çeşitli türlerine karşı olan derin ilgi, haklı bir şekilde onun zengin, samimi, şiirsel içeriğinde, güçlü iradesinde, ahlaki safığındadır. Hafızayı güçlü tutmaları bir şekilde anlatıyı aktarmalarına ve sık sık o anlatıyı tekrar etmelerine bağlıdır. Bu halkın içinde her birey, aktif katılım içinde olmak zorunda olup kimse tüm bireylerin bütünleşmiş olarak bulunduğu bu halk kitlesinin içinden ayrımazdı ki sözlü kültürün anımsama ve bellekte tutma işlevi buna bağlıydı.

Birincil sözlü kültürlerde özenle incelenmiş bir düşünceyi koruyup anımsama sorununa geçerli çözüm, belleğe yardımcı olan, ağızdan çıkmaya hazır düşünce biçimleri kullanmakla mümkündür. Düşüncenin ritmik, dengeli tekrarları ya da antitezleriyle, kelimelerdeki ünsüz ve ünlü seslerin uyumuyla, sıfatlar ve başka kalıpsal ifadelerle aktarılması, herkesin sık duyup kolaylıkla hatırlayabileceği şekilde biçimlenmiş olması gerekir. Ciddi düşünce, bellek sistemleriyle iç içedir. Belleği güçlendirme zorunluluğu, söz dizimini bile koşullandıır (Ong, 2013: 50). Örneğin,17.yy saz şairlerinden; Âşık Halil, Âşık Ömer, Benli Ali, Ercişli Emrah, Gevherî, Kayıkçı Kul Mustafa, Kâmilî, Kâtibî, Köroğlu, Kuloğlu, Öksüz Âşık, Sun'î, Şahinoğlu, Tameşvarlı Âşık Gazi Hasan, Üsküdârî, Yazıcı... vs gibi.

Ercişli Emrah şiirlerinde bu söz diziminden kaynaklanan ahengi, şiirlerindeki yapı taşlarında oluşturmuştur. Şiirlerin ahenkli ve ritimli tekrarları sözlü kültürde düşünceyi yayma işlevi üstlenmiştir.

Sözlü kültürlerde uzun süreli ve sözlü temele dayanan düşünceler ağırlıklı olarak şiir vasıtasıyla dile getirilmiştir. Bu şiirler, âşıklar tarafından hem hece hem de aruz vezni şeklinde resitatif bir terennüm tarzında söylene gelmiştir. Heceli tür ve nazım şekilleri olarak, mani, koşma ve destan olmak üzere üç nazım şeklinden faydalanmışlardır. Aruz vezni olarak da en çok kullandıkları divan/divani türleridir.

Eski şiir sanatı mirası uzun bir değişim sürecinden geçmiştir ve bu süreç bugün de çeşitli düzeylerde devam etmektedir.

Daha az veya daha çok yetenekli her anlatıcı, şarkıcı, masalcı vs. bu eserlerin şeklini ve içeriğini veya bazen konusunu değiştirerek onlarda kendi sanatsal ruhunu bırakır. Aktarma sürecindeki bu bireysel izdüşümleri günümüz bilimsel çalışmaları için çok değerlidir (Sokolov, 2009: 25).

Âşık şiiri bağlamında bir âşığın, şiirinin ve mesajının icra bağlamında dinleyicide uyandırmasını beklediği duygusal tepkilere yönelik olarak ezgiyle bütünleşen ve geleneksel olarak kalıplaşmış konuyu ele alış tarzı farkılış̧maktadır. Bir başka deyişle konunun ele alınış tarzı âşığın anlatım tutumuna göre belirlenmektedir (Çobanoğlu, 2011, 301).

\section{Ercişli Emrah: Yaşamı ve Sanatı}

Âşık tarzı edebiyat geleneğinin temsilcilerinden Ercişli Emrah, şiirlerini özentisiz bir dille ve ağırıklı olarak hece vezniyle ifade etmiştir. Bu ifade tarzında yaşadığı yer ve yaşadığı yüzyıl eğitimli âşık 
almasına mani olmuştur. Babasından ve çevresindeki âşıklardan feyiz alarak aşk, tabiat, sosyal içerikli şiirler yazmıştır. Emrah'ın hayatıyla ilgili net bir bilgi olmamasına rağmen, halk arasında ve edebiyat araştırmacıları tarafından şöyle anlatılmaktadır:

Ercişli Emrah, 17. yy'da Erciş'te yaşamış ünlü bir aşk hikâyesinin hem kahramanı, hem de Türk Halk Edebiyatı'nın ünlü saz şairlerinden biridir. Şiirlerinde; Emrah, Sefil Emrah, Dertli Emrah diye anılmaktadır. Kelime anlamı itibariyle de Emrah Arapça "Amrak", yani yoksul, sefil..vs. anlamları taşımaktadır. Bölgede bu kullanıma yakın Âşık Emrah ve Kul Emrah mahlaslarının kullanııdığı da görülmektedir.

Bu mahlasların Emrah tarafından mı yoksa meddahlar tarafından mı kullanıldığı bilinmemektedir. Bugün hayatı hakkındaki bilgiler Ercişli Emrah ile Selvihan Hikâyesi ve bir iki küçük belgeye dayanmaktadır. Hikâye anlatıcısı, meddah, âşık ve halk hikâyecilerinin anlattığına göre o, âşık bir babanın çocuğudur ve pîr elinden bade içmiştir (Saraçoğlu, 1999: 9-63).

Ercişli Emrah'ın yaşadığı çağı saptamaya çalışan ilk araştırmacı Ziyaeddin Fahri'dir. Ziyaeddin Fahri (Fındıkoğlu), Ercişli Emrah'ı Erzurumlu Emrah ile çağdaş sayarak XIX. yüzyılın ikinci yarısı olarak saptamalarda bulunmuştur. O dönemde, Eflatun Cem (Güney) ve Köprülüzade (M.F. Köprülü) de bu kanıyı paylaşırlar. Bu yüzden Köprülüzade: XVIII. belki de XVII. Asırda yaşadığını öne sürdüğü Emrah adlı âşıkla Ercişli Emrah'ın birlenmesini yadsır ve bu konuda sonuna dek ikircimli kalır.

Sakaoğlu'nun Ercişli Emrah tespitleri ikircimli kalan yazarları ikna edebilecek güçtedir. Şöyle ki; mevcut bir belgedeki "Erciş Kubünde yetişmiş derd-i zar ile bağrı yanık Karakoyunlu âşıklarındandır" ifadesi, onun yaşadığının en güzel delilidir. Babası Âşık Ahmet'in şiirleri de günümüze kadar gelebilmiştir. Sakaoğlu diğer bir kanıtı da şöyle beyan etmiştir: 1986 yılında Erciş'te yapılan bir kazı sonunda, onun, Selbi'nin ve sazının çizgilerinin yer aldığı bir hece taşının bulunması, Emrah ile ilgili bazı soruların cevaplandııımasını sağlamıştır (Sakaoğlu, 2013: 143).

Ercişli Emrah'ın XVII. Yüzyılın ilk yarısında yaşadığı görüşünde olan araştırmacı ve antoloji düzenleyicileri arasında Behcet Necatigil, İlhan Başgöz, Nejat Birdoğan, Cahit Öztelli, Cemil Yenir, Tahir Kutsi (Makal), Ali Püsküllüoğlu vardır.

Kendisi de Ercişli olan Ali Saraçoğlu'nun araştırmaları sonucu Ercişli Emrah'ın yaşadığı dönemi XVI. Yüzyııın sonu ile XVII. Yüzyılın ilk yarısı olarak öne sürmektedir. Diğer önemli bilgiyi M. Fuad Köprülü gün ışığına çıkarmıştır. Ercişli Emrah'la ilgili ilk araştırmayı Murat Uraz yapmıştır.

Erciş'li Emrah'ın yaşadığı çağ üstüne görüş öne süren son araştırıcı Saim Sakaoğlu'dur. Sakaoğlu da Ercişli Emrah'ın XVII. Yüzyılda yaşadığı fikrine katılmaktadır.

Ercişli Emrah'ın yaşadığı yüzyıl üstüne öne sürülen ve yazılı belgelere dayanmayan bu savların etken fikri genelde, Ercişli Emrah'ın şiirlerinin dil ve biçem (ûslup) özelliğine, halk anlatılarına ve Emrah ile Selvi/Selbihan hikayesindeki tarihi olaylara dayandırılmaktadır (Saraçoğlu, 1999: 40). Bu konuda Prof. Pertev Naili Boratav, bütün yönleriyle âşık geleneğinin özelliklerini en iyi gösteren yaratmaların "Sevgi Hikayeleri” olduğu görüşündedir ve Ercişli Emrah gerçeğine referans olarak gösterilebilmektedir (Boratav, 1946: 40).

Boratav sevgi hikayelerini şöyle aktarmaktadır; gerçekten yaşadıkları kesinlikle bilinen ya da yaşamış olduklarına inanılan âşıkların (halk şairlerinin) romanlaşmış hayatlarını anlatan hikaye(ler)dir. Âşık Garip, Ercişli Emrah, Kerem, Karacaoğlan vb. pek çok tanınmış âşıkların hayatları bu çeşit hikâyelerinde anlatılmıştır.

Boratav, Azeri ve Terekeme göçmenlerin rivayetleri esas alındığında halk âşıklarını yaşadıkları zamana göre:

1. Tufarkanlı Abbas 


\section{Dede Kasım \\ 3. Kurbanî \\ 4. Ercişli Emrah}

Olarak sıralamayı yapmıştır. Diğer âşıkların Ercişli Emrah'tan sonra geldiğini yaptığı sınıflamada belirtmiştir. Ki zaten şiirlerinin şekil özelliği de bu halk rivayetlerine hak verdirecek biçimdedir. Bunları, şiirlerin şekilleri bakımından 16. Asırdan daha eski devirlere çıkarmaya imkan yoktur.

\section{Ercişli Emrah, Erzurumlu Emrah Farklılıkları}

Diğer önemli bir konu ise Ercişli Emrah'la Erzurumlu Emrah'ın birbiriyle karıştırılıyor olmasıdır. Yapılan araştırmalar sonucunda Erzurumlu Emrah'ın 19. yy'da yaşadığı, Ercişli Emrah'ın şiirlerinde Türkçeyi, Erzurumlu Emrah'ın ise Arapça, Farsça ve Türkçe karışımı bir dil kullandığı tespit edilmiştir. Yine araştırmacıların birçok tespiti sonucunda, aralarında 200-250 yıl zaman farkı olan bu iki halk ozanının birbiriyle karıştırımasının önüne geçilmiştir. Ölümü ile ilgili bilgiler de yine hayatı etrafında oluşan hikâyeden ve son yıllarda yapılan araştırmalardan elde edilmiştir.

Araştırııılar, iki Emrah'ın şiirlerinin ayırt edilmesi hususunda, ortaya bazı ölçütler koymuşlardır. Buna göre; Erzurumlu Emrah'ta divan şiirinin etkisi görülür; oysa Ercişlinin şiirleri bütünüyle halk şiiri tarzındadır. Erzurumlu Emrah'ın medrese öğrenimi görmüş olmasına karşılık, Ercişlinin öğrenim durumu hakkında bilgimiz yoktur; ancak babası da âşık olduğu için, onun sınırlı da olsa eğitim aldığını söyleyebiliriz.

Ercişli Emrah'ın bâdeli olmasına karşılık, Erzurumlu bâde içmemiştir. Ercişli; din, tasavvuf, ezel, ebed, varlık, yokluk, bu dünya, öbür dünya gibi kavramlarla hiç ilgilenmemiş, bütünüyle bu dünyanın adamı olmuştur. Erzurumlu ise din ve tasavvuf konularıyla da ilgilenmiştir.

Erzurumlu medreseye devam ettiği için halk şiiri türlerinin yanında divan, kalenderî, semaî ve gazel gibi türlerde de yazmıştır. Onu bu yönüyle bir âşıktan daha çok "kalem şairi" sayabiliriz. Ercişli Emrah ise aruzu bilmemektedir, şiirlerinin tamamını hece vezni ile söylemiştir. Erzurumlu Emrah, Nakşibendî tarikatinin halidiye koluna bağlıdır. Bu sebepten yukarıda da belirttiğimiz gibi ezel-ebed ve tasavvuf konuları, şiirlerinde sıklıkla işlenmiştir. Ercişli Emrah'ın ise herhangi bir tarikatle bağı yoktur.

Erzurumlu Emrah'ın özellikle aruzla yazdığı şiirleri yabancı tamlamalarla, Arapça ve Farsça asıllı kelimelerle doludur. Ercişlinin şiirlerinde ise Azerbaycan Türkçesi ve Van'ın Erciş ilçesinin ağız özellikleri görülür. Ercişli Emrah araştırıcıları onun bütün şiirlerine ulaşamamışlardır. Erzurumlu Emrah'ın ise elimizde divanı bulunmaktadır. Ercişli Emrah'ın şiirleri Erzurumlu Emrah'ın dışında Karaca Oğlan, Bayburtlu Zihnî ve Develili Seyrânî ile de karışmıştır. Yazılı kaynakların yetersizliğinden dolayı söz konusu âşıkların hayatı ve tüm eserleriyle ilgili net bir ifade kullanılamamaktadır. Söz konusu bilgilerin büyük çoğunluğu sözlü kültürden hafızalarda kalmış olanlardır.

Ercişli Emrah'ın hayatı etrafında oluşan Ercişli Emrah ile Selvihan Hikâyesi sevda konulu hikâyelerdendir. Oysa Erzurumlu Emrah'ın hayatı etrafında böyle bir hikâye oluşmamıştır. Ercişli Emrah'ın şiirlerinde Van Ercişten Saat/Sahat Çukuru (Iğdır) ve İran'a doğru bir yolculuk söz konusu iken, Erzurumluda Karadeniz sahillerinden Çankırı, Konya, Niğde, Sivas ve Tokat'a doğru bir yolculuk işlenmiştir. Ercişli Emrah'ın mezarının Erciş'te olduğu rivayetlere dayanırken; Erzurumlunun mezarı, Tokat'ın Niksar ilçesindedir.

Ercişli Emrah'ın elimizdeki şiirleri 150 kadardır; Erzurumluda ise bu sayı çok daha fazladır.Bütün bu hususlar da Ercişli Emrah'ın şiirlerinin çok azının cönklerde olmak üzere, daha çok sözlü kaynaklarda tespit edildiğini göstermektedir.Ercişli Emrah'ın elimizde bulunan şiirlerinde aşk, tabiat, sevgili ve gurbet gibi konular işlenmiştir. Onun şairliğini Ali Saraçoğlu ve Saim Sakaoğlu etraflıca incelemişlerdir. Hayatı etrafında oluşan Ercişli Emrah ile Selvihan Hikâyesi ise Muhan Bali tarafından değerlendirilmiştir. Bugün Doğu Anadolu Bölgesi'ndeki âşıklar Ercişli Emrah'ın hikâyesini anlatmanın 
yanı sıra, şiirlerini de ezbere bilmektedirler. Ercişli Emrah, doğup büyüdüğü Erciş ilçesinde değişik zamanlarda düzenlenen bilimsel toplantı ve törenlerde çeşitli yönleriyle değerlendirilmiştir. ${ }^{2}$

Ercişli Emrah'ın 17.yüzyılda Erciş'te yaşamış bir halk aşığı olduğu hayat hikayesinin anlatıldığı, bölge kültüründe destanlaşmıştır. "Emrah ile Selbihan Hikâyesi” Türk halk hikâyeleri arasında geniş bir coğrafyada bilindiği gibi, Emrah da şiirleri ile başta Türkiye ve Azerbaycan olmak üzere birçok Türk yurdunda tanınan ve bilinen Türk Halk Edebiyatı'nın ünlü saz şairlerindendir.

\section{Ercişli Emrah Şiirlerinin Sanatsal Yönü}

Emrah ile Selvi/Selbihan adlı hikâyenin de kahramanı olan Emrah, Türk Saz Şiirinin önemli temsilcilerinden biridir. Dilinde de zamanımıza çok yaklaşmış bir olgunluk olduğu görülür. Şiirleri, Erciş şivesine dayalı bir duruluğa sahiptir. Şiirlerine herkesin anlayabileceği berrak, duru bir Halk Türkçesi hâkimdir. Söyleyişi içtendir. Halk zevkine yakın bir söyleyişi vardır. Aradan 300-350 yıl gibi bir zaman geçmesine rağmen bütün Anadolu'da anlatılan Emrah ve Selbihan adlı hikâye, bugün bile Halk Edebiyatına ilgi duyanlar tarafından derlenmekte, şiirleri ile ilgili çalışmalar sürdürülmektedir. Bununla ilgili olarak birçok varyant ortaya çıkmış, şiirleri yeniden yayınlanmıştır. Emrah ile Selbihan hikâyesinin yurt içinde ve dışında değişik varyantları bulunmaktadır. Halk Türkülerinin büyük bir çoğunluğu yaşanmışlıklar üzerine kuruludur.

Toplumun genelini ilgilendiren bir tarihi, sosyal veya kültürel bir olay türkülerin konusu olabileceği gibi, bir çobanın, bir köylü delikanlının, yoksul insanların umutsuz aşkları, sevenlerin ayrılıkları, hazin aşk öyküleri, gurbet ve ölüm olgusu türkülerin odak noktasını oluşturabilmektedir (Mirzaoğlu, 2015: 9). Ercişli Emrah, halk tarafından içselleştirilmiş ve sahiplenilmiş bir aşk şairi olmakla birlikte varyantlaşmalar ve hakkında söylenenler, şiirlerini başka âşıklara mâl edilmesine rağmen, halkın dilinde ve yüreğinde hâlâ etkisini sürdürmüş ve şiirlerinin bestelenmesiyle ortaya çıkan türkülerin geniş kitlelere ulaşmış olduğu bilinen bir gerçekliktir. Âşık müziği de temelini anonim halk müziği gelenekleriyle dinî tasavvufî tekke müziğinden almıştır. Müzik ile şiirin, bir başka deyimle saz ile sözün birbirini bütünlemesi, şiirlerinde büyük çoğunlukla hece vezninin kullanılması ve türkü formuna titizlikle uyulması âşıklık geleneğinin başlıca özelliğidir ${ }^{3}$.Bu sebeple halk şiiri örneklerini Türk halk türküsü formundan ayrı düşünmek doğru değildir.

İlk ezgiler, mitik ve epik karaktere sahipken Anadolu sahasında bir lirizmin yoğunluğu görülür. Eskiden az perdeli, en çok iki ses aralığını kapsayan ezgili söyleyişler, zamanla dört ve daha çok perdeli yapıya kavuşmuştur. ${ }^{4}$

\footnotetext{
${ }^{2}$ Ali Berat Alptekin, Türk Halk Şiiri, Kaynak: http://www.turkceciler.com/sairler/ercisli.html

${ }^{3}$ Atınç Emnalar, Tüm Yönleriyle Türk Halk Müziği Ve Nazariyatı, Ege Üniversitesi Basımevi, İzmir 1998, s. 232

${ }^{4}$ Ali Uçan, “Geçmişten Günümüze-Günümüzden Geleceğe Türk Müzik Kültürü”, IV. Uluslar Arası Türk Kültür Kongresi, Atatürk Kültür Merkezi Yay. Ankara 1997
} 


\section{Ercişli Emrah ve Selbihan Hikâyesi (Âşık Ummani Poyrazoğlu Derlemesi: Kısa Özeti)}

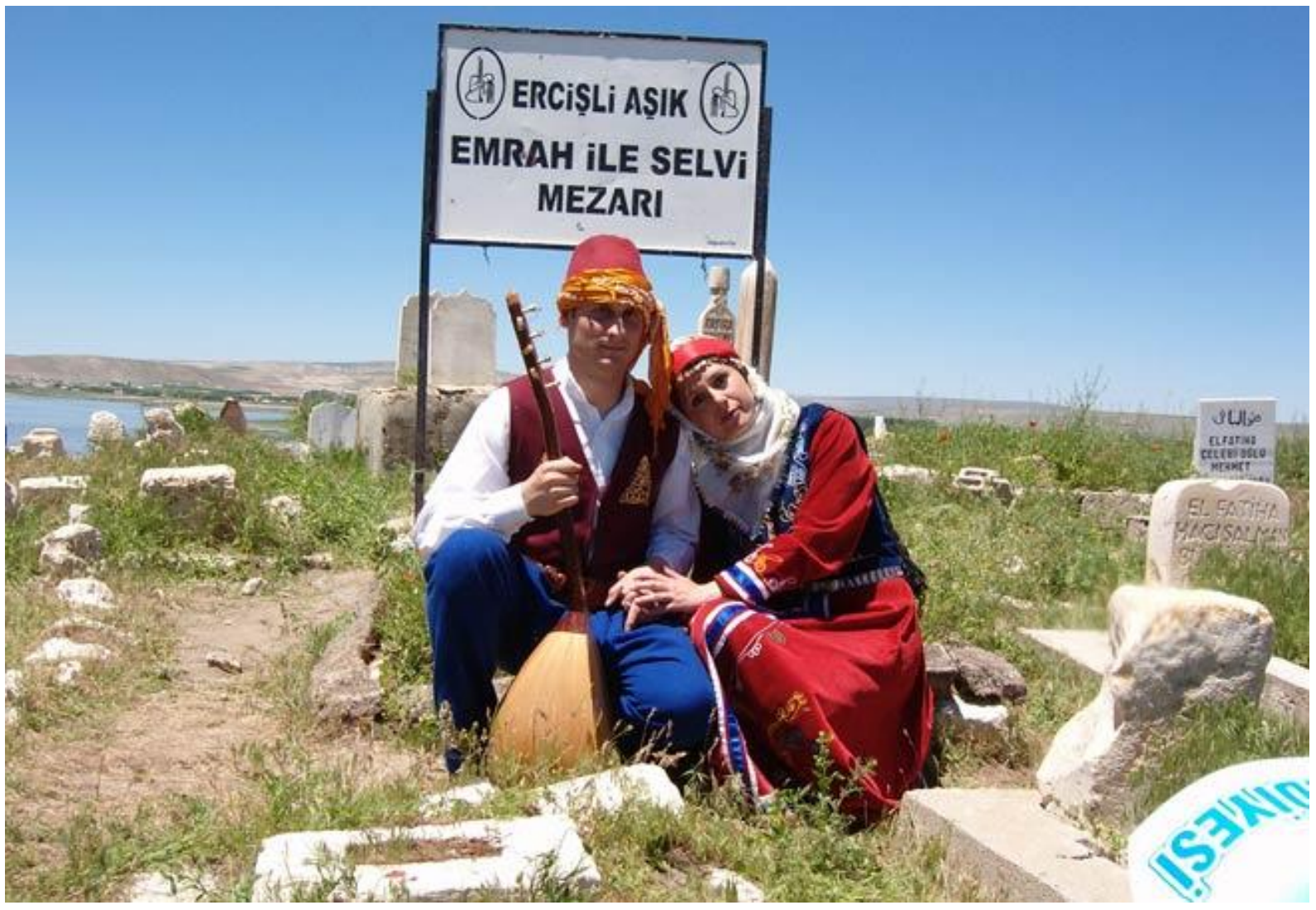

Resim 1: Ercişli Emrah Temsili Kabir

16.yüzyılın sonları ile 17.yüzyılın başları, Osmanlı İmparatorluğunun içte ve dışta birçok sorunla karşı karşıya kaldığı dönemdir. İçte ayaklanmalar ve kargaşa sürerken bu arada İran Şah'ı Şah Abbas da Osmanlı toprakları üzerinde hâkimiyet kurmak için ordularını gönderiyor, şehir ve kaleler işgal ediliyordu. İşte böyle bir ortamda Osmanlı Devleti'nin doğusunda yer alan ve Osmanlı'nın kale kentlerinden biri olan Erciş'te de büyük bir aşkın ilk kıvılcımları atılıyordu. Erciş Kale Bey'i Miroğlu Ahmet Bey'in Divan Âşığı Âşık Ahmet'in oğlu Emrah, rüyasında pîr elinden bade içerek, kale beyi Miroğlu Ahmet Bey'in kızı Selbihan'a âşık oluyordu. Sonra bu aşk büyüdükçe büyüdü. Aşk büyüdükçe ayrılıklar ve acılar da ardından gelmeye başladı.

\section{Bir nazenin bana gel gel eyledi \\ Varmasam incinir varsam incinir \\ Nazik ellerinnen ince belinnen \\ Sarmasam incinir sarsam incinir}

Bir gün Osmanlı topraklarına giren Şah Abbas, Van Kalesi'ni kuşatır. Fakat kale halkı, dayandıkça dayanır. Sonunda Şah Abbas pes eder ve geri dönmeye karar verir ama geri dönerken askerleri de Erciş Kalesi'ne saldırır. Kale Beyi Miroğlu Ahmet Bey öldürülür ve kızı Selbihan da İsfahan'a kaçırıır. Bir süre sonra Emrah da konağa gelir. Gelir ki ne görsün? Miroğlu Ahmet Bey öldürülmüş, konağı yağmalanmış, Selbihan ise kaybolmuştur. Emrah üzüntüsünü içine atar ve Selbihan'ı Erciş'de aramaya başlar.

Yüz bin dert çekmişem bin daha gerek

Çok ömür ister ki bir daha görek

Yarım elden aldı o zalım felek

Hoyrat dost bağınnan gül aldı gitti 
Selbihan'ı Erciş'te bulamayan Emrah, Selbihan'ın kaçırıldığını anlayınca anası ve babasıyla helalleşerek yollara düşer. Ovaları, yaylaları, dağları yol edinir kendine. Bu arada geride anasıla babası yalnız kalmışlardır. Onları da aklından çıkaramaz. Fakat Selbihan aşkına yollara düşen Emrah için artık geri dönüş yoktur.

\title{
Katar katar olmuş giden durnalar \\ Sizler de bilirsiniz hâllarımızı \\ Sılada sevdiğim öz anam atam \\ Deyin gözlemesin yollarımızı
}

Mecnun'u Leyla için çöllere, Ferhat'ı Şirin için dağlara, Kerem'i Aslı için gurbete düşüren aşk, Emrah'ı da yollara düşürür. Dağlara, turnalara, seher yeline seslenerek Selbihan'ı bulmaya çalışır.

\author{
Emrah emeklerin olmasın heba \\ Kuluna yardımcı Hazret-i Mevla \\ Ricam budur sennen ey bad-ı Saba \\ Emrah geldi diye bir haber eyle
}

Bu arada Şah Abbas Selbihan'la evlenmek ister. Selbihan, zaman kazanmak için bir şart koşar. Şah bir bağ yetiştirecek, bağ barını verince de onunla evlenecektir. Aradan yedi yıl geçer. Emrah, Selbihan'ın izini süre süre İsfahan'a varır. İsfahan'da dügün şenlikleri kurulmuştur. Şah Abbas'ın Selbihan'la düğün hazırıkları yapılmaktadır. Emrah, Şah Abbas'ın yanında kendisine yardımcı olsun diye götürdüğü Sahat Çukurunun Bey'i Yakup Han'ın yardımıyla Şah'ın huzuruna çıkar. Saz çalıp şiir söylerken Selbihan'ın sevgilisi olduğunu ima eder.

Emrah der ki, tundan tuna atılım

Kul olup da her diyarda satılım

Selbi'nin elinden yandım, yakıldım

Sende bencileyin yanarsın Şah'ım

Bunun üzerine Şah onların birbirlerini sevdiklerini ve badeli âşıklar olduğunu anlar, Selbihan'ı Emrah'a vermeye razı olur. Fakat Şah'ın Hanları buna itiraz ederek Emrah'a zehir içirip badeli âşık olup olmadığını denemek isterler. Emrah, Selbihan'ın elinden içeceğini söyler. Kendisinden emindir.

\section{Emrah der ki yar elinden naçaram \\ El uzatır tülbendini açaram \\ Şahlar zeher verse korkmaz içerem \\ Ko desinler öldü bir yara sebep}

Şah Emrah'ı denedikten sonra ona hazırladığı güveylik elbisesini ve bir ferman vererek değişik hediyelerle birlikte düğününü yapmak üzere Yakup Han'la Erciş'e gönderir.

Emrah, yolda Yakup Han'ı Sahat Çukuru'nda kalmaya razı ederek Selbihan'la birlikte Erciş'e gelir. Düğünden önce köşk yapmaya başlar. Fakat Emrah, köşk yapımıyla uğraşırken kardeşleri Selbihan'ı Tiflis Hanı olan amcaları Ko Han'ın yanına kaçııılar. Orada Selbihan'ı amcalarının oğlu ile nişanlarlar. Bunu haber alan Emrah, babasının ısrarı üzerine onu da yanına alarak tekrar yollara düşer. Bu arada birçok yere yolu düşer.

Ağalar gurbetten geldim

Geldim ki nazanım getmiş

Sılam bana hor göründü

Salınıp gezenim getmiş 
Sonunda Selbihan'ı Tiflis'te bulurlar. Emrah,Selbihan'ı bulup hasret giderirken yakalanıp zindana atılır. Ko Han, Emrah'ın başını vurduracakken hanları araya girerek önce Emrah'ın dinlenmesini, sonra da suçu varsa cezalandııımasını isterler. Emrah sazını alır, başından geçenleri anlatır ve kendisine Şah tarafından ferman verildiğini belirterek sözlerini bağlar.

\section{Bize Emrah derler Karakoyunnu \\ Namertler içinde yiğit oyunnu \\ Kaz kimin pısmanık erkek boyunnu \\ Biz Türkük Türklükten demanımız var}

Emrah, derdini anlatırsa da, Ko Han onun başını vurdurmaya kararlıdır. Çünkü ferman Erciş'te kalmış, ayrıca Ko Han Selbihan'ı da oğluyla nişanlamıştır. Bunun üzerine Âşık Ahmet, mecburen İsfahan'a giderek durumu Şah Abbas'a anlatır. Şah Abbas'ın emriyle Yakup Han, bir grup askerle Tiflis'e gelerek Emrah'ı kurtarır ve Erciş'e dönerler. Fakat bu defa Erciş yakınlarında önlerine İran Çapakurları çıkar. Emrah onlara başından geçenleri anlatır. Yorgun, bitkin ve perişan haldeki Emrah'ın anlattıklarına inanmayan ve Selbihan'ı Emrah'a yakıştıramayan Çapakurlar, Selbihan'ı alır, götürürler.

Bu duruma çok üzülen Emrah, babasıyla birlikte Erciş'e hareket eder. Erciş'te hastalanan ve yataklara düşen Emrah, bir gün ölüm halinde hasta yatarken aniden doğrularak babasından duvarda asılı duran sazını ister."Baba, Selbihan'ın kokusu geliyor "diyerek bir türkü söyler. Bu onun son türküsü olur.

$$
\begin{aligned}
& \text { Emrah'ın sevdiği Selbi sen misen } \\
& \text { Sağ elin sinemde gezdiren misen } \\
& \text { Ağır salacamı götüren misen } \\
& \text { Namazım kılmaya yar sefa geldin }
\end{aligned}
$$

Türkü bittiğinde Selbihan karalar giyinmiş bir halde odaya girer. Emrah Selbihan'ın geldiğini görür ve gözlerini Selbihan'a doğru çevirir. Uzun uzun bakışırlar. Selbihan, Emrah'ın elini tutmak için yanına yaklaşır. Fakat Emrah, o esnada ruhunu teslim eder. Bunu gören Selbihan feryat ederek çığlıklar atar. Selbihan'ın bu çı̆̆lıkları günlerce Erciş Ovasında yankılanır.

Emrah'ın naaşı mezara konulurken Selbihan cemaatin önüne geçer. "Ey cemaat edeceğim duaya âmin deyin" diyerek ellerini açar ve Allah'ın kendi canının da alması için dua eder, sonra da kendisini Emrah için açılan mezarın içine atar. Yanyana iki mezar açılır. Mezarlardan birisine Emrah'ı, diğerine de Selbihan'ı koyarlar.

Rivayete göre, o günden sonra Selbihan'ın mezarı üzerinde beyaz güller, Emrah'ın mezarı üzerinde ise kırmızı güller açmaya başlar. Yıllarca yörenin kızları bu gülleri kopararak niyet tutmuşlardır 5 . Hikaye, kısaltılmış ve üzerinde bazı düzenlemeler yapılmıştır. Bölge âşıkları tarafından anlatılan doğrultuda aktarıımıştır.

Âşık Ömer Ummani Poyrazoğlu ile yaptığımız görüşme neticesinde Ercişli Emrah araştırması yapan ve hakkında yazılanları toparlayıp, Ercişli Emrah gerçeğini kitaplaştıran Ali Poyrazoğlu ile diğer âşıkların anlatıları tutarlı görülmüştür. Ali Poyrazoğlu, sözlü kültür ve yazılı kültürden faydalanarak hazırladığı Ercişli Emrah ile ilgili ilk kaynağı Kültür Bakanlığı tarafından yayınlanmıştır.

Âşık Ummani; "Ercişli Emrah, bir çok değerli âşığın doğmasına vesile olarak çok uzun süre âşıkığın Erciş'de yaşatıldığını ve atışmaların bölge sözlü kültürünü önemli bir yere getirdiğini, yaptığımız derleme çalışmaları sırasında aktarmıştır. Kendisinin de Emrah'a ithafen yazdığı şiirleri mevcuttur. Çocukluk yıllarında ilk şiir denemelerine başlamış olan Ummâni Poyrazoğlu, yine kendi ifâdesine göre 1956 (20 yaş) yılında görmüş olduğu bir rüya neticesinde "pîr elinden bâde içmiş"tir. Burada söz konusu olan rüya motifi "Âşık Edebiyatı " içerisinde önemli bir yere sahiptir.

\footnotetext{
${ }^{5}$ Selahattin KOŞAR, Timurleng_6511-30-2014, 05:43 AM ve Âşık Ömer Ummani Poyrazoğlu ile derlemeden alıntı
} 
Umay Günay'ın Âşık Tarzı Şiir Geleneği ve Rüya Motifi adlı eserinde verdiği bilgilere göre, "Türk Halk Edebiyatı'nın bütün mahsullerinde sık sık rastlanan rüya motifi, Türk halk edebiyatında rüya motifinin fonksiyonu ve mahiyeti hakkında detaylı bilgileri mevcuttur.

Âşık Ummani'nin aktarımlarından hareketle, "pîr elinden bâde içmeyenin âşıklığı tartışmalı, noksandır", demesi söz konusu kanıyı desteklemektedir. Ercişli Emrah'ın bâde içmesiyle birlikte, rüyasında gördüğü Selbi'ye âşık oluşu eş zamanlıdır. Emrah ile Selvi/Selbihan Hikayesi, Türk Halk Hikâyeleri arasında geniş bir coğrafyada bilinmektedir. Hikâyelerde Emrah'ın Selvi/Selbihan adlı sevgilisine kavuşmak için yollara düşen, ayrılıklara ve acılara katlanan bir âşık olduğu belirtilir.

Hikâyenin ikinci önemli kahramanı Selvi/Selbihan ise Erciş Kale Beyi Miroğlu Ahmet Bey'in çok uzun saçıı (Rapunzel gibi) kızıdır. Emrah şiirlerinde, sözlü aktarımı dikkate alarak şöyle diyebiliriz; babasını model aldığı çocukluk yıllarında kendini ispatlama kaidesiyle ironi ve hiciv ağılıklı şiirler seslendirirken, rüyada pîr elinden bâde içip Selbi'ye âşık olduktan sonra şiir tarzında değişiklik meydana gelmiştir. Aşk üzerine çalıp söylediği türküler/şiirler daha fazladır.

Hikayenin bölge halkı tarafından benimsenmesi ve yaygınlaşması, edebiyat dünyasına kazandırımasıyla birlikte Emrah'ın aşk şiirleri daha çok öne çıkmıştır. Bestelenen şiirlerinin büyük çoğunluğu da aşk üzerinedir. ${ }^{6}$

\section{Van Türkülerinde Erciş Türkülerinin Yeri}

Ülkemizde bazı yerler vardır ki, bağlı oldukları merkezlere diğer parçalarından daha çok özellik ve değer katarlar. Söz gelimi Malatya kültürü ve müziği Anadolu kültürüne çok değerler katmış özel bir şehirken yanında Arguvan'ı katmadığımız zaman Malatya eksik kalır. Öyle ki, Arguvan çoğu zaman Malatya'nın önüne geçer. Bu gibi örnekler ülkemizde çoktur. Erzincan-Tercan, Denizli-Acıpayan, Ankara-Keskin, Sivas-Zara vb. Bu örneklerden biri de Van-Erciş'tir.

Erciş'de, yüzyıllar öncesinden gelen ve günümüzde de çok sayıda temsilcileri bulunan önemli bir halk ozanı geleneği mevcuttur. Erciş, 17. Yüzyılda büyük halk ozanı Ercişli Emrah'ı yetiştirmiştir.

Günümüzde öne çıkan isimlerin başında Âşık Davut Telli, Halil Kanter ve Ömer Ummani Poyrazoğlu gelmektedir. 1967 yılında TRT tarafından yapılan folklor derlemesinde Van ve Ercişten kayıtlar alan Muammer Sun ve Cenan Akın, o yıllarda Erciş'de yaşayan halk ozanları ve türkücülerden Mehmet Tanrıverdi, Yusuf Dumaner, Eczacı ve Milletvekili Mehmet Erdinç, Emin Telli (Âşık Cihani), Hafız Ahmet Kendir, Mehmet Turan, Sıdık Baş, Ahmet Acar gibi isimlerden ses kaydı almışlardır.

Bu derleme çalışmasında önemli bilgilere ulaşılmıştır. Şanlıurfa'da "Sıra Geceleri", Diyarbakır'da "Velime Geceleri", Elazığ'da "Kürsübaşı Alemleri", Orta Anadolu'da "Yaren Geceleri", Van'da "Oturma Geceleri" olarak geçen gece eğlencelerine o yıllarda Erciş'de "Divanhane" diye adlandırılmıştır (derleme,Murat Oto, 2015).

Bu kayıtlarda yine Erciş'te yaşadığı rivayet edilen âşık Gurbani ve Âşık Ömer'den şiirler okunmaktadır. Kaval, mey ve zurnanın yaygın olduğu, ilginç olarak da Tulum çalındığı, tulumun ucuna takılan çift başlı kavala "çelemeşk" dendiği belirtilmektedir.

Türkücülere "Yırcı",türkü söylemeye de "yırlamak" dendiği belirtilmektedir. Kışın evlerde bulgur öğütülürken türküler yanında bilmeceler sorulduğu ve bu bilmecelere de "tapmaca"dendiği belirtilmektedir. Tarihi belgeler ve bu kayıtlar gösteriyor ki Erciş genel halk kültürü folklor yönünde derin bir kültüre sahip olduğu gibi geleneksel halk müziğinde de köklü ve derin bir kültüre sahip bir bölgedir. Bu kültürü günümüze taşıyan yani güncelleştiren isimlerin başında Mehmet Bülbül gelmektedir. 1941 Erciş doğumlu Bülbül, daha dokuz yaşındayken toylarda (düğünlerde) türküler söylemeye başlamıştır.

\footnotetext{
${ }^{6}$ Murat Oto, “Geçmişten Geleceğe Van Türküleri I”, İstanbul, Soylu Matbaa, ve Yayınevi, 2013
} 
Kendinden önceki nesillerde yetişen âşıkların türkülerini ezberleyerek, düğünlerde seslendirmiştir. Birçok türkünün kayıtlı kaynak kişisi pozisyonundadır. Kayıtlara geçmiş yaklaşık 122 Erciş türküsüne kaynaklık yapmışır. TRT sanatçısı ve aynı zamanda Ercişli olan Atakan Çelik ve Hüsamettin Subaşı, Mehmet Bülbül'den derlenen türkülerle ün yaptığı söylenmiştir.

$\mathrm{Bu}$ iki önemli ses sanatçısı dışında günümüzde mahalli ve ulusal platformlarda başarı ile Erciş türkülerini kitlelere akataran önemli ses sanatçıları vardır. Celal Yarıcı, Hüsamettin Ergül, Metin Elibol, Cahit Engin, Ünal Zorer, Yaşar Turan, Mahmut Dokumacı, Ahmet Poyrazoğlu ve Ummani Baba gibi âşıklık geleneğinin temsilcileri ve ses sanatçıları yerel ve ulusal anlamda Ercişli Emrah kültürünü ulusal boyutta aktarmaktadırlar.

Erciş müzik kültürü denince "demeli-çevirmeli"diye adlandırılan, ülkemizin birçok yerinde örnekleri olmakla birlikte Erciş kadar yoğun kullanılmayan bir çeşit icra biçiminden bahsetmek gerekmektedir. Eski dönemlerde çalgıcıların az bulunmasından kaynaklı olarak Anadolu insanının yaratıcılığının bir unsuru olan demeli-çevirmeli türkü okuma, o günkü koşullardaki zorunluluklardan doğmuş bir icra biçimidir. Toylarda konukların gövengi (halay) yı devam ettirecek yırcılar, günlerce bu ortamda türküler söylerlerdi. Bu türkülerin bazen tek, bazen iki bazen de üçlü satırları bir çeşit nakarat (çevirme) gibi meclisin tamamına söyletilmesi ile ortaya çıkan bu icra formunda ilk yırcı söylemekte (deme), sonra diğer yırcı veya meclis tekrarlamaktadır (çevirme). Deme-çevirme faslı gövenk sürdüğü sürece devam etmekte, bu süre içinde yırcının mahareti ile o anda irticalen (doğaçlama) olarak dörtlükler yazılmakta, bazen yörenin mani kültürü ile o ezgi sürdürülmektedir. Bu kültür günümüzde çalgı kültürünün gelişmesi ve çalgı çalanların sayısının artması nedeni ile yok olmuş durumdadır. Bu kültürden üretilme türküler ise klasik türkü formunda notalandırıımıştır. Bu kültürü günümüzde yaşatmaya çalışan Mustafa Dokumacı ve Mehmet Bülbül, birlikte okudukları birçok demeli-çevirmeli türküye birlikte kaynak kişi olmuşlardır.

\section{Ercişli Emrah'ın Bestelenen Şiirleri}

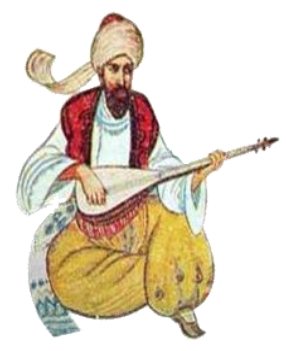

Resim 2: Ercişli Emrah Temsili

Ercişli Emrah'a ait olan birçok şiir, değişik sanatçılar tarafından bestelenerek radyo ve tv'lerde okunmaktadır. Bunlardan bazıları şunlardır: "Tutam Yar Elinden, Bir Yiğit Gurbete Gitse, Dedim Dedi, Seherden Uğradım Göl Kenarına, Bir Nazenin Bana Gel Gel Eyledi, Bizim Sahraların Başı, Ağalar Gurbetten Geldim, Bugün ben Bir Güzel Gördüm, Gine Bahar Oldu Coştu Yüreğim, Çıktım Yücelere Seyran Eyledim, Bad-ı Seba,Sen Mevlayı Seversen, Katar Katar Olmuş Giden Turnalar".

Bestelenmiş daha fazla şiiri olmasına rağmen notaya alınan çok az şiiri vardır. Notaya alınmış ve seslendirilmiş şiirleri günümüzdeki manaları göz önüne alınarak değerlendirilmiştir. Şiirlerin ezgisel bütünlüğü ve eser formu ise çok farklı aktarımlar arasından mevcut notalar üzerinden ve yaşadığı varsayılan dönem özellikleri göz önüne alınarak incelenmiş ve analiz edilmiştir. Emrâh'ın sesi ve sazı, şiirlerindeki müziksel öğeler ve özellikle halk musikisinin doğup gelişmesinde çok önemli bir yer tutan duyguların (gurbetin kahrı, sıla hasreti, sevgili özleyiş vs...) işlenişi, Türk musikisi repertuarına birçok güzel eser kazandırmıştır. Edebiyat dünyasında şiirleri ile yaşayan Ercişli Emrâh'ın Türk halk musikisi içindeki yerini de göstermek amacı ile eserleri tesbit edilip, makam yada dizilerine göre tasnif edilmiş, kullanılan usuller incelenmiştir. 


\section{Bestelenmiş Bazı Şiirlerinin Ezgi Yapıları}

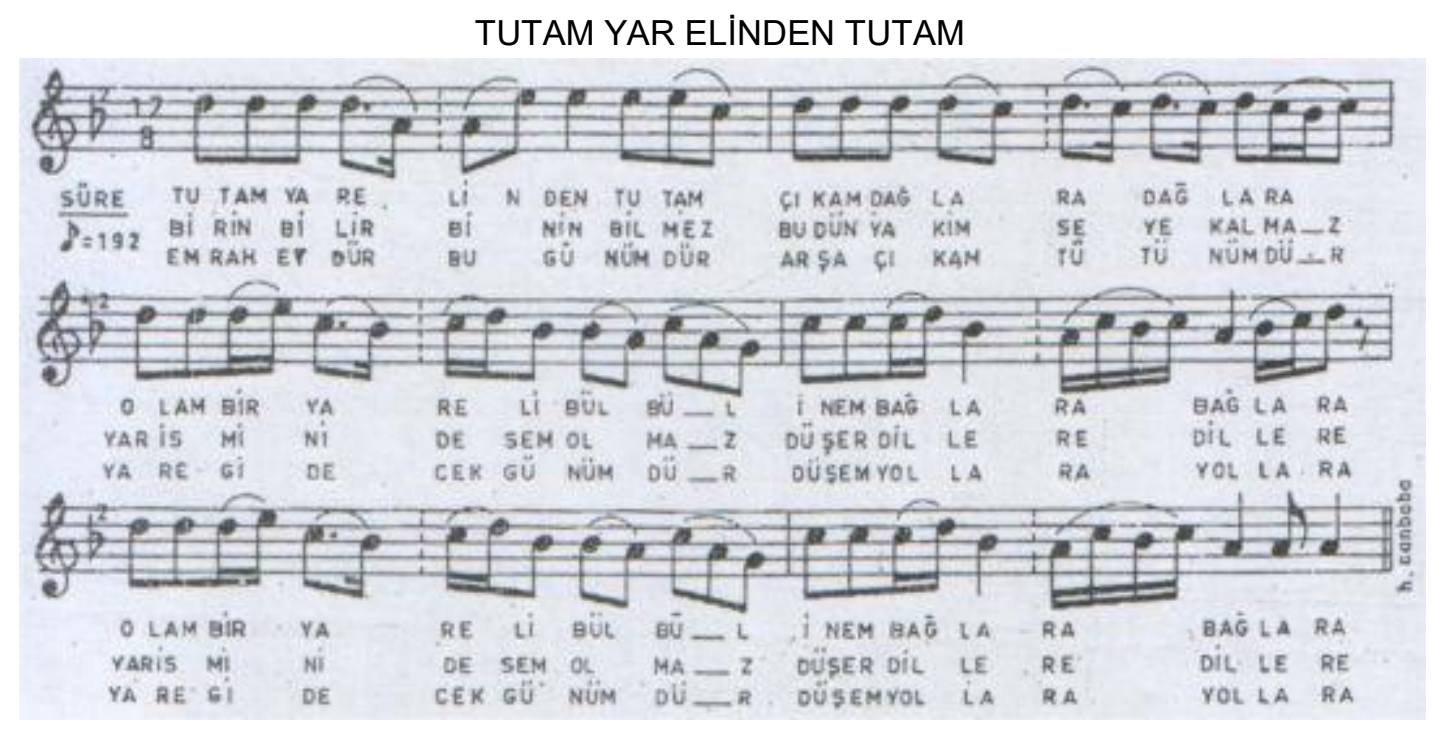

Nota 1: Aşık Ercişli Emrah Bestelenmiş ve Notaya Aktarılmış Şiiri “Tutam Yar Elinden Tutam”

Tutam Yar Elinden Tutam Türküsü: 12/8'lik Türk müziğinde bileşik kalıplı bir ritimdir. Bu ritim ağırlıklı olarak doğu-güneydoğu Anadolu'da yaygın olarak kullanılmaktadır. Yani $3+3+2+2+2$ bileşik usulüyle bestelenmiştir. Türkünün makamsal yapısı; kerem ayağıdır ve adını Âşık Kerem'den almıştır. Sade bir ezgi yapısı vardır. Âşık şiirinin ezgili yapısı ve sazı kullanmış olduğunu gösteren yukarıdaki notada; söz, ritim ve ezgi akışı birlikteliğinin tutarlı dengesi görülmektedir.

\section{BADE-I IÇERLER NAZINAN}

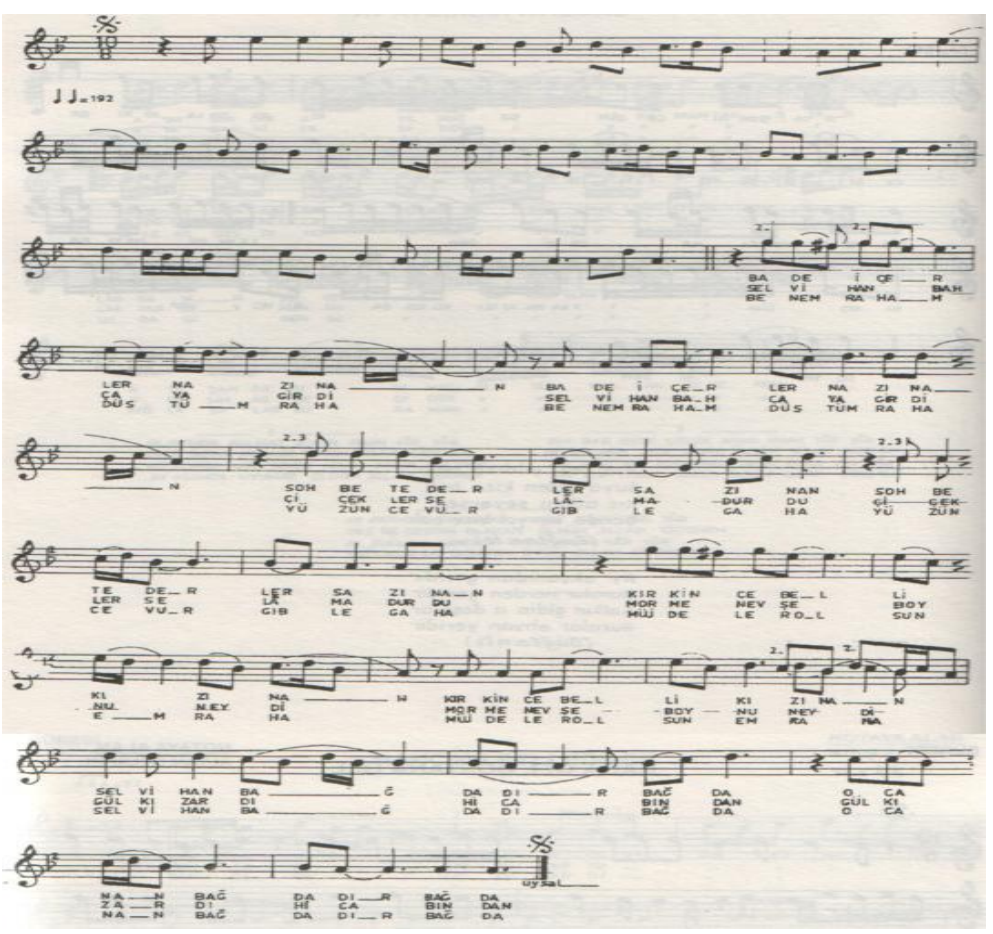

Nota 2: Âşık Ercişli Emrah Bestelenmiş ve Notaya Aktarılmış Şiiri “Bade-i İçerler Nazınan" 
Şiir ve ezgi uyumlu ve sade bir biçimdedir. Karma onikili usûller grubuna giren türkü iki tane $5 / 8^{\prime}$ lik yani, 2+3+2+3 şeklinde bestelenmiştir ve sekizlik süreye tekabül eden 192 metronom kullanılmıştır. Türkü makamsal yapısı kerem ayağıdır (üç tür kerem ayağı vardır; engin kerem, kesik kerem, yahyalı kerem).

\section{ESME SEHER YELI}

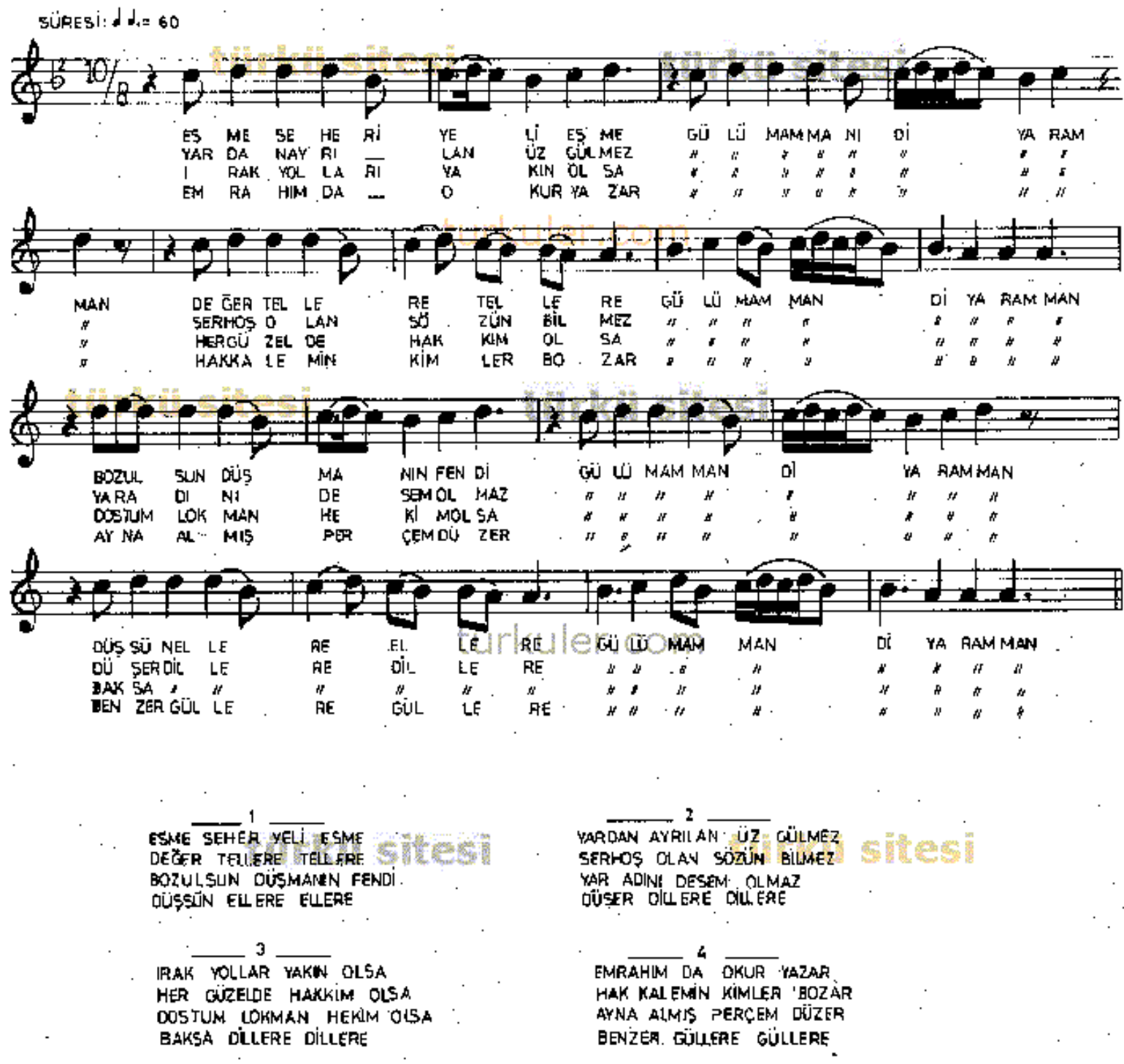

Nota 3: Âşık Ercişli Emrah Bestelenmiş ve Notaya Aktarılmış Şiiri "Esme Seher Yeli Esme”

Esme Sehar Yeli Esme Türküsü: Şiir ve ezgi uyumu basit ve akılda kalıcıdır. Karma onikili usûller grubuna giren türkü iki tane 5/8'lik yani, $2+3+2+3$ şeklinde bestelenmiştir ve sekizlik süreye tekabül eden 192 metronom kullanılmıştır. Türkü makamsal yapısı kerem ayağıdır (üç tür kerem ayağı vardır; engin kerem, kesik kerem, yahyalı kerem). 


\section{SALINDI BAHÇEYE GIRDI}

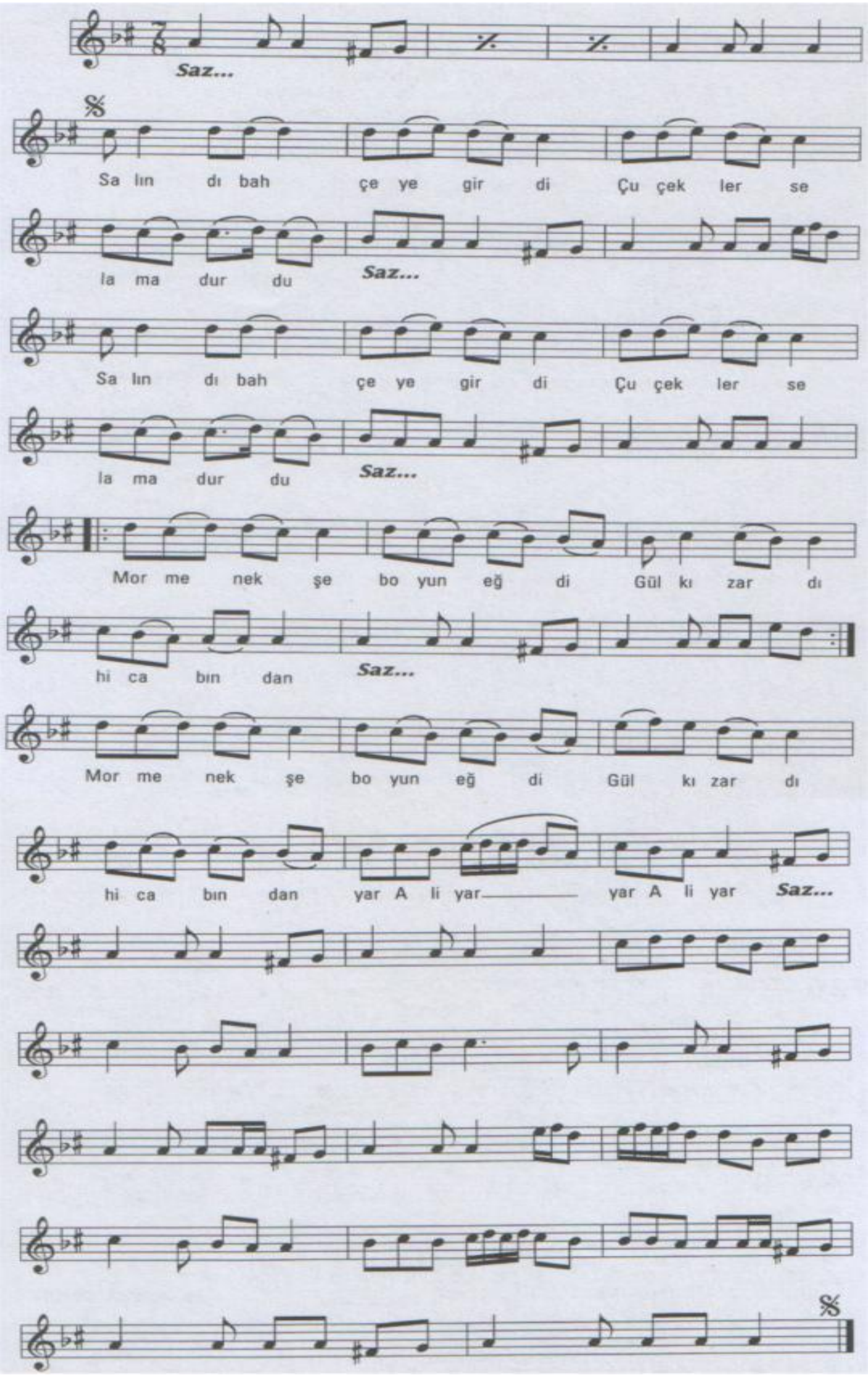

Nota 4: Âşık Ercişli Emrah Bestelenmiş ve Notaya Alınmış Şiiri "Salındı Bahçeye Girdi" 
Salındı bahçeye girdi türküsü bileşik usülde, garip ayağında bir türküdür. Yani 2+2+3 usulünde bestelenmiştir. Türk müziğinde karakteristik hicaz makamına denk gelmektedir.

Ali Saraçoğlu'nun Ercişli Emrah adı kitabının 180.sayfasında yayımlanan şiir (Salındı Bahçeye Girdi) üç dörtlük olup bu haliyle yer almaktadır. Türkü TRT Repertuarında iki dörtlük olup 4135 No ile kayıtlıdır.

\title{
Salındı Bahçeye Girdi
}

\author{
Salındı bahçeye girdi \\ Çiçekler selama durdu \\ Mor menekşe boyun eğdi \\ Gül kızardı hicabından \\ Bahçenin kapısın'açtım \\ Sandım ki cennete düştüm \\ Ben o dosttan ayrı düştüm \\ Elin dilinden dilinden \\ Bahçenin kapısı güldür \\ Dalında öten bülbüldür \\ Sefil Emrah sana kuldur \\ Bağışla geç günahından
}

Kaynak Kişi:Mehmet Selvi, 2186 No ile TRT Repertuarında yer alan (Evvel Bahar Yaz Ayları Gelende) türkünün kaynaktaki sözleridir. Türkü Ercişli Emrah'a aittir.

\section{Evvel Bahar Yaz Ayları Gelende}

Evvel bahar yaz ayları gelende Açılmış bahçende nar memelerin Versen de ağzıma emsem Bal ile yoğrulmuş yar memelerin

Açma göğsün açma rakip bakıyor

Yar senin ateşin beni yakıyor

Tenin misk ü amber olmuş kokuyor

Al benim yağlığım sar memelerin

Ecel kuşu gelip başa konanda

Tenim çıkıp teneşirde yunanda

Biçare Emrah da bir gün ölende

Mezarım taşına sür memelerin

Saz Şiiri Antolojisi, Vasfi Mahir Kocatürk, "Başlangıçtan Bugüne Kadar Türk Edebiyatının Saz Şiiri Tarzında Yazıımış En Güzel Şiirleri" başlığıyla, Ayyıldız Matbaası, Ankara - 1963, s.208-209

\section{Kömür Gözlüm Ateşine Düşeli}

Kömür gözlüm ateşine düşeli Didem kan-yaş döker dilim dad eyler Garip yerde yad ülkede sevdiğim Bana senden özge kim imdad eyler 
Ta ezelden oldum gamlar düşgünü

Ben feleğe minnet etmem üç günü

Yarim ne beklersin elin köşkünü

Felek ya dağıtır ya barbad eyler

Yatamadım nazlı yarin dizine

Doya doya bakamadım yüzüne

Uyma Selbi'm uyma eller sözüne

Seni mennen meni sennenyad eyler

Ayrılık şerbeti ölümden acı

Gel söyle sevdiğim nedir ilacı

Kendine mülk sanma tahtınan tacı

Felek ne umdurur ne abad eyler

Gine rengin aldı dağlar lalesi

Yıkılmış yapılmaz gönlün kalesi

Emrah'ın çektiği aşkın belası

Ne alır canımı ne azad eyler

Kaynak Kişi: Ali Saraçoğlu - Ercişli Emrah(Şad OI Deli Gönül Müjdeler Olsun) Kültür Bakanlığı Yayınları, Ankara 1999, s.257

\section{Şad OI Deli Gönül Müjdeler Olsun}

Şad ol deli gönül müjdeler olsun Gelecektir benim yarim bu gece

Kesilsin kurbanlar yansın çıralar

Talan olsun bütün varım bu gece

(Talan olsun küll-i malım bu gece)

Gül dibinden gelen şadlık ünüdür

Yüreğimde tüten yar tütünüdür

Arefe geçmiştir bayram günüdür

Dedim kurban olsun canım bu gece

(Dedim yare kurban canım bu gece)

Emrah'ın sevdiği hanlar hanıdır

Al yeşil giymiştir canlar canıdır

Koynunda memeler kiraz benidir

Dedim ver ağzıma emim bu gece

\section{Sonuç}

Genel halk müziğinde olduğu gibi Van türkülerinde de bu kültürün sonraki nesillere ve zamanlara aktarılmasında en önemli unsur kaynak kişilerdir. Bu kültürü günümüze aktaran ve bu bağlamda kent kimliğinin oluşmasındaki gizli kahramanlardan olan genelde halk ozanı olan kaynak kişilerin önemli bir çoğunluğunun müzik eğitimleri akademik anlamda yeterli düzeyde değildir. Bu nedenle genelde meşk usûlü ustasından öğrenerek çırağına aktarılan türkülerin kayıt altına alınıp unutulmamasını sağlayan derleyicilerin de o kültürün gelişmesinde önemli katkı sağladıkları unutulmamalıdır. Kaynak kişilerin 
bölge kültürünü korudukları fakat yeterli mali desteklerinin olmamasından kaynaklı eğitim alamadıklarını, Ercişli Emrah şiirlerini bestelemede yetersizliklerden dolayı uluslararası boyutlarda tanıtamadıkları serzenişleridir. Festivallerde yapılan tanıtımların bölgesel düzeyde kaldığı ve hala Ercişli Emrah ile ilgili olumsuz anlamda tartışmaların sürmesinden kaynaklı mezar taşının bile müzeye kaldııııp halktan uzaklaştırılmaya çalışılması bölge halkına saygısızlık olarak nitelendirildiği, Erciş halkından aldığımız dönütlerdir. Bölgenin yerel ve ulusal sanatçıları tarafından Ercişli Emrah tanıtımının yetersiz olduğu, günümüz araştırmacıların yapıtlarında Ercişli Emrah'dan üstünkörü söz etmeleri, büyük ozan, saz şairinin ileriki yıllarda sözlü kaynakların ortadan kalkmasıyla ve yazılı kaynağın yetersizliğinden dolayı kaybolması endişesi taşıdıkları belirlenmiştir. Ercişli Emrah ve Selbi hikayesinin günümüz teknolojisiyle sinemaya ve tiyatro sahnesine taşınması ölümsüzleşmesini sağlayacaktır. Şiirlerinin bestelenmeye devam etmesi ve TRT repertuarına kazandırılması, bölge sanatçıları dışındaki ses sanatçılarının da repertuarında yer alması Ercişli Emrah türkülerinin yaygınlaşmasını sağlayacaktır. Ayrıca Van Yüzüncüyıl Üniversitesi Güzel Sanatlar Fakültelerinin ve Türk Müziği Devlet Konservatuarının Ercişli Emrah'ın bestelenmiş şiirlerini incelemeye alması gerekmektedir. Diğer bir araştırma sonucu; TRT repertuarında ve müzik sitelerinde Ercişli Emrah şiirlerinin Yöresi yanlış nakledilmiştir, gerekli düzenlemelerle güncellenmesi gerekmektedir.

\section{Kaynakça}

1. BORATAV, P. Nâilî, (1995), 100 Soruda Türk Halk Edebiyatı, İstanbul, Gerçek Yayınevi.

2. ÇOBANOĞLU, Özkul, (2011), "Halk Edebiyatına Giriş", Eskişehir, Anadolu Üniv. Yayınevi, S.294-301.

3. EMNALAR,Atınç, (1998), "Tüm Yönleri ile Türk Halk Müziği ve Nazariyatı", İzmir, Ege Üniversitesi Yayınları.

4. GÜNAY,Umay,(1999), “Türkiye'de Âşık Tarzı şiir Geleneği ve Rüya Motifi”, Ankara,.GÜNAY,Umay," Âşık Tarzı Şiir Geleneği ve Rüya Motifi”, Ankara ,T.C. Atatürk Kültür, Dil, ve Tarih Yüksek Kurumu Atatürk Kültür Merkezi Yayını, Sayı 16, s.107-108

5. KOŞAR, Selahattin, Timurleng 65 11-30-2014, 05:43 AM

6. MiRZAOĞLU, F. Gülay,(2015), "Halk Türküleri”Konu-İcra-Yapı-Anlam-İşlev, Ankara, $\quad$ Akçağ Yayınevi.

7. ONG, Walter J.(2013), "Sözlü ve Yazılı Kültür"SözünTeknolojileşmesi”, İstanbul, Metis yayınevi.

8. OTO, Murat, (2013),"Geçmişten Geleceğe Van Türküleri I", İstanbul, Soylu Matbaa ve Yayınevi.

9. ÖZBEK, Mehmet, (1994), "Folklor ve Türkülerimiz", İstanbul.

10. POYRAZOĞLU, Ömer Umman; derleme, Van/Erciş 30.11.2015

11. SAKAOĞLU, Saim, (1986), "Emrâh'ın Hayatı ve Hakkında Yapılan Yayınlar", Erciyes, s.101, Mayıs 1986, s.5 ve (2013), Türk Dili Dergisi “Türk Şiiri Özel Sayısı”Sayı: 445- $\quad 450, \quad 1989$, TDK Yayınları

12. SARAÇOĞLU, Ali, (1999), "Ercişli Emrah", Kültür Bakanlığı Yay, Ankara, s. 9-63

13. SOKOLOV, Yuri M, (2009), "Folklor: Tarih ve Kuram"(Çev.Yerke Özer),Ankara, Geleneksel Yayınevi, s. 25

\section{Makaleler}

1. BORATAV, Pertev Naili, "Âşık Edebiyatı", Türk Dili Türk Halk EdebiyatıÖzel Sayısı, Ankara, 1968.

2. Ercişli Ozan Ahmet Poyrazoğlu'nun "Bir Heybe Şiir" Kitabı Erguvan yayınlarından çıkmıştır. Sayfa sayısı 324, baskı yılı 2013, ayrıca Ercişli Emrah ile Selbihanhikayesini de aynı yayınevinden çıkarmıştır. Sayfa sayısı 279, yayın yılı 2006

3. SAKAOĞLU, Saim, (1996), "Saz Şiiri Tarihimize Genel Bir Bakış", 50.Kültür ve Sanat

4. Yılında Dr. Mehmet Önder'e Armağan / Milli Kültür Araştırmaları,117-128, Ankara,

5. _ _ , "Türk Saz Şiiri”, Türk Dili, (Türk Şiiri Özel Sayısı III / Halk Şiiri), 1989. 
6. _ , "Atasözleri ve Deyimlerimizdeki Yabancı Asıllı Kelimeleri

7. Türkçeleştirebilir miyiz?”, Türk DünyasıAraştırmaları,33,Aralık,131-140, 1984b.

8. KÖPRÜLÜ, Fuad, "Saz Şairleri: Dün ve Bugün”, 165-193, Ankara, 1986a.

9. _ Türk Edebiyatında Âşık Tarzı'nın Menşe' ve Tekâmülü, Edebiyat Araşıırmaları,195- 238, Ankara, 1986b.

10. Prof.Dr. Ali Berat ALPTEKIN, Türk Halk Şiiri

11. http://www.turkceciler.com/sairler/ercisli.html

12. https://www.youtube.com/watch?v=YXxiECsGMv4 (Ercișli Emrah video) 